\title{
Combined Selective Cerebral Hypothermia and Mechanical Artery Recanalization in Acute Ischemic Stroke: In Vitro Study of Cooling Performance
}

\author{
G. Cattaneo, M. Schumacher, J. Wolfertz, ${ }^{D}$ T. Jost, and ${ }^{(D)}$ S. Meckel
}

\begin{abstract}
BACKGROUND AND PURPOSE: Therapeutic hypothermia represents a promising neuroprotective treatment for patients with ischemic stroke. Selective, intracarotid blood cooling may initiate rapid and early brain hypothermia, reduce systemic effects, and allow combined endovascular mechanical thrombectomy. For this approach, a balloon cooling catheter system was designed and studied in vitro to optimize its cooling performance.
\end{abstract}

MATERIALS AND METHODS: Computational fluid dynamics of blood cooling was performed within the common carotid artery lumen by using 3 different catheter designs (1-, 2-, and 4-balloon array). On the basis of these results, a first catheter prototype was manufactured, and its heat-exchange performance was tested in an artificial in vitro circulation simulating the common carotid artery lumen at different flow rates (inflow temperature of $37^{\circ} \mathrm{C}$ ).

RESULTS: In the computational fluid dynamics model, the catheter with the 4-balloon array achieved the highest cooling rate of $-1.6^{\circ} \mathrm{C}$, which may be attributed to disruption of the thermal boundary layers. In the in vitro study, cooling of the blood substitute at flow rates of $400 \mathrm{~mL} / \mathrm{min}$ (normal common carotid artery flow) and $250 \mathrm{~mL} / \mathrm{min}$ (reduced common carotid artery flow due to distal MCA occlusion) achieved a temperature drop inside the blood substitute along the cooling balloons of $-1.6^{\circ} \mathrm{C}$ and $-2.2^{\circ} \mathrm{C}$, respectively.

CONCLUSIONS: The feasibility of intracarotid blood cooling using a new catheter system was demonstrated in vitro. A serial 4-balloon array led to an optimized cooling capacity approaching optimum target temperatures of mild therapeutic hypothermia. To determine the therapeutic efficacy of combined selective therapeutic hypothermia and mechanical thrombectomy, further in vivo studies by using a model of temporary ischemia with large-vessel occlusion and recanalization are required.

ABBREVIATIONS: $C C A=$ common carotid artery; $\mathrm{MT}=$ mechanical thrombectomy; $\mathrm{TH}$ = therapeutic hypothermia

$\mathrm{T}$ herapeutic hypothermia $(\mathrm{TH})$ has become a clinical standard in patients with successful resuscitation after cardiac arrest and in neonates with severe asphyxia, to increase the rate of favorable neurologic outcome and reduce mortality. ${ }^{1-4}$ Neuroprotection provided by $\mathrm{TH}$ affects multiple aspects of brain physiology during all stages of ischemia (eg, excitotoxicity, apoptosis, inflammation, free radical production, blood

Received February 6, 2015; accepted after revision March 31.

From Acandis GmbH \& Co. KG (G.C., J.W., T.J.), Pforzheim, Germany; and Department of Neuroradiology (M.S., S.M.), University Hospital Freiburg, Freiburg, Germany.

This work was sponsored by Federal Ministry of Education and Research, Germany (Federal Ministry of Education and Research grant 13GW0015B).

Please address correspondence to Stephan Meckel, MD, Department of Neuroradiology, Neurocenter, University Hospital Freiburg, Breisacher Str 64, D-79106 Freiburg, Germany; e-mail: stephanmeckel@gmail.com

-- Indicates open access to non-subscribers at www.ajnr.org

http://dx.doi.org/10.3174/ajnr.A4434

flow, metabolism, and blood-brain barrier integrity). ${ }^{5}$ Recently, the feasibility and safety of $\mathrm{TH}$ in patients with acute ischemic stroke was proved in controlled studies, ${ }^{6-9}$ and 2 multicenter, randomized clinical trials (European Stroke Research Network for Hypothermia-1 and Intravenous Thrombolysis plus Hypothermia for Acute Treatment of Ischemic Stroke $2 / 3)^{10,11}$ are currently underway to study its efficacy. Until now, $\mathrm{TH}$ in patients with acute stroke has been applied only systematically by surface cooling, intravenous cooling, or cold saline infusions.

In patients with acute ischemic stroke related to large-artery occlusions, rapid treatment with mechanical thrombectomy (MT) by using stent retrievers for vessel recanalization reduces mortality and improves functional outcome according to the recent release of landmark randomized controlled trials. ${ }^{12-14}$ However, reperfusion of ischemic brain tissue may also induce additional tissue damage and hemorrhagic trans- 


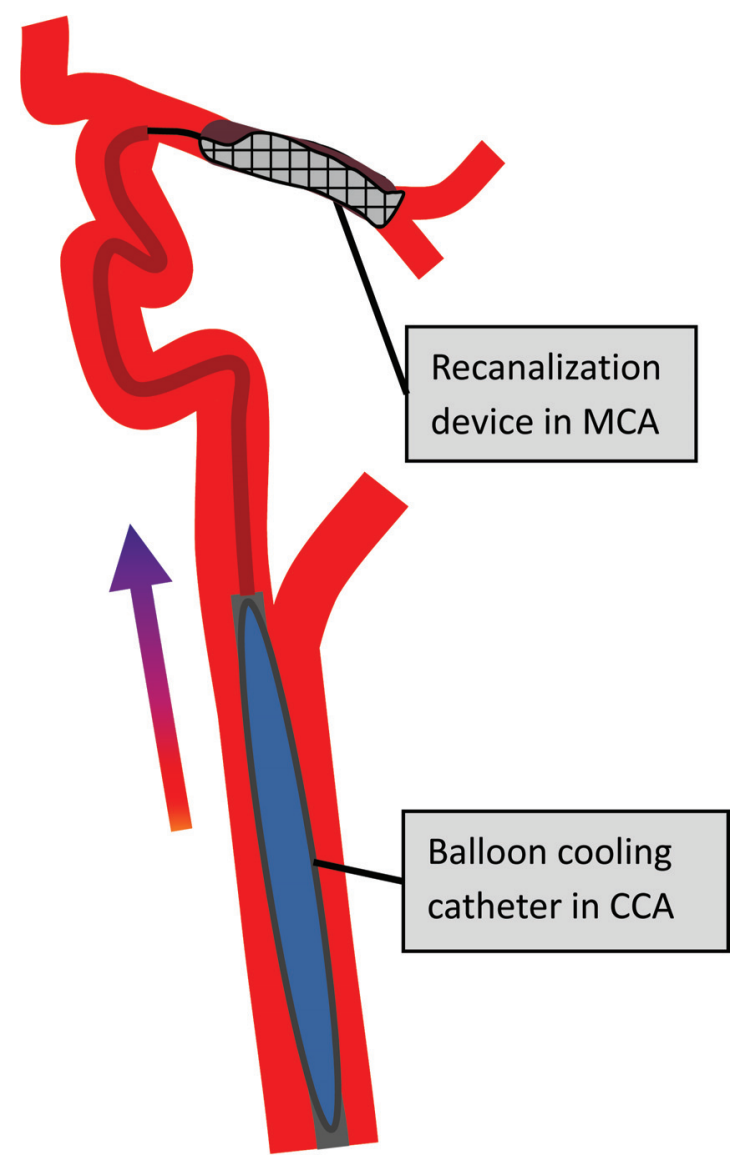

FIG 1. Schematic illustration of combined simultaneous intracarotid blood cooling in CCA and MT procedures by using a stent retriever device for the treatment of acute MCA occlusion. The colored arrow indicates transfer of cooled blood to ischemic brain and penumbra via collateral arteries before the MT procedure with the stent retriever device placed across MCA occlusion.

formation, which potentially limit the benefits of such recanalization therapies. ${ }^{15}$ Although the neuroprotective effects of TH may positively modulate mechanisms responsible for reperfusion injury, current systemic cooling approaches involve long induction times so that the therapeutic window may still be missed for many patients. ${ }^{16}$

We aimed to develop a combined approach of selective cerebral TH and MT within a single procedure by using a cooling catheter system that will be positioned in the common carotid artery (CCA) and proximal ICA and simultaneously serve as access for the intracranial MT procedure (Fig 1). Thus, cooled blood may first reach the ischemic penumbra via collaterals before recanalization and then further provide a "cold reperfusion" of the ischemic core during and after recanalization treatment of the occluded cerebral arteries. Moreover, this approach of selective TH may enable an earlier and faster induction of brain cooling and the reduction of systemic adverse effects of TH (ie, pneumonia) compared with systemic cooling techniques. In particular, early initiation of TH before or during vessel recanalization therapy is expected to be a critical determinant of clinical outcome. ${ }^{10}$

Before in vivo testing, the goal of this numeric and experimental in vitro study was to assess the feasibility and optimize the

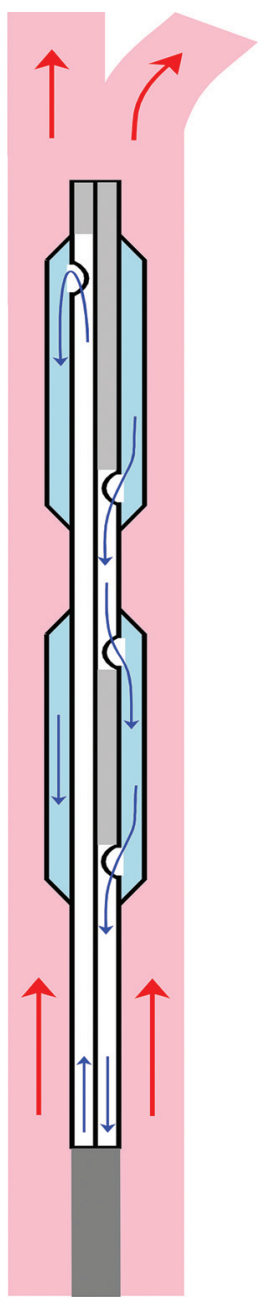

FIG 2. Schematic of the cooling catheter system as a heat exchanger between streaming blood and closed-loop circulation of cooling fluid inside the catheter. Blue arrows represent flow pathways of cooling fluid inside the inlet and outlet catheter lumen, with diversion from distal to proximal into 2 adjacent balloons. Red arrows represent the blood flow direction from the CCA into the ICA and external carotid artery.

blood cooling performance of the newly developed balloon cooling catheter system for TH within the CCA lumen.

\section{MATERIALS AND METHODS \\ Concept of Heat Exchange with the Balloon Cooling Catheter System}

The balloons at the tip of the catheter system act as a heat exchanger between the bypassing blood stream and the separated cooling fluid circuit inside the cooling catheter, which is schematically depicted in Fig 2. The cooling fluid is circulated from the inlet lumen up to the distal catheter tip and then diverted within the outlet lumen, where openings to the balloons are provided that allow heat exchange with the bypassing blood via thin balloon surface membranes. In case of a multiple balloon array at the catheter tip, the balloons are serially connected with the direction of cooling fluid flow from distal to proximal. Thus, the catheter outlet lumen is interrupted between the openings of each balloon to prevent cooling fluid flow from bypassing the balloons. The third central lumen designed for delivery of catheter systems for MT is not depicted in the schematic. 


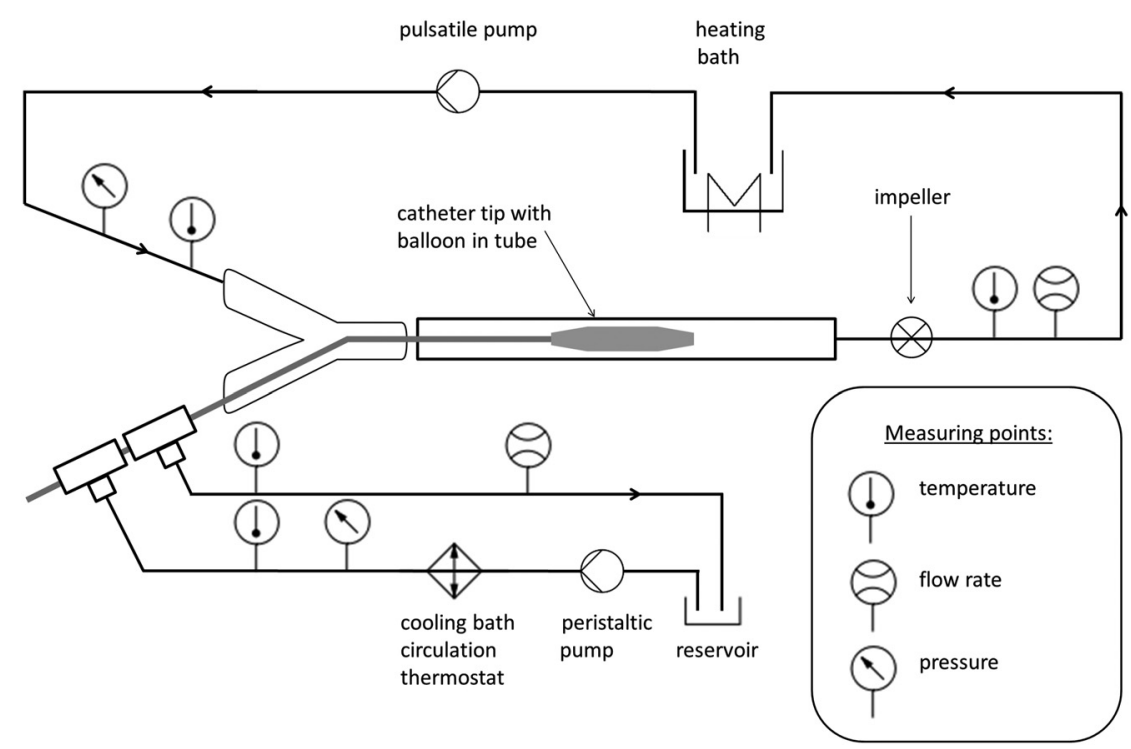

FIG 3. Schematic illustration of a bench test array for in vitro analysis of balloon cooling catheter system performance.

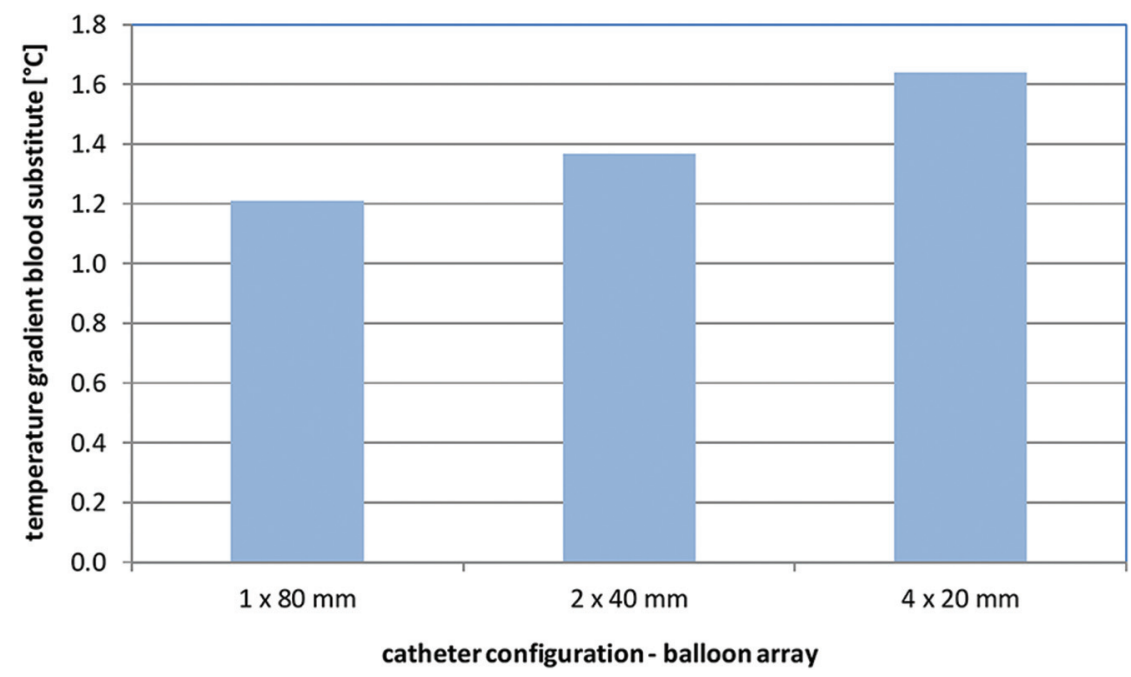

FIG 4. Temperature gradient across heat exchange balloons with 3 different balloon arrays. was immobile and centered in a rigid vessel that represented a simplified geometry of the CCA (7-mm diameter). An adiabatic behavior of the vessel wall was assumed; hence, heat transfer with the surrounding tissues was not considered. The rheology of the human blood was depicted through the Power Law model, by using the blood fluid parameters provided in the SolidWorks data base.

Closed-loop circulation of the cooling fluid (normal saline) inside the balloon catheter was provided by a simplified symmetric 2-lumen catheter, as shown in Fig 2. We set the cooling fluid temperature to $10^{\circ} \mathrm{C}$ at the inlet of the computational domain, considering an estimated heat loss of $4^{\circ} \mathrm{C}$ along the whole catheter length. The blood inlet temperature was set to $37^{\circ} \mathrm{C}$. Blood and cooling fluid flow rates were set to 400 and $100 \mathrm{~mL} / \mathrm{min}$, respectively. Flow was steady for both fluids.

The bulk-average blood temperature (area- and flow-rate-weighted average) was calculated proximal and distal to the balloon array at the cooling catheter tip. Because of steady-state flow conditions, the temperature calculation was performed time-independently.

\section{In Vitro Artificial "Blood Circuit" Testing}

An artificial "blood circuit" was constructed with an internal diameter of 7 $\mathrm{mm}$, compatible with the human CCA (mean diameter, $7.4 \mathrm{~mm}^{17}$ ); the artificial blood circuit was made of PVC tubes (Guttasyn Kunststoff, Witten,

\section{Numeric Simulation}

A numeric calculation of the fluid flow and heat transfer was performed by using the computational fluid dynamics software SolidWorks Flow Simulation 2013 SP3.0 (Dassault Systèmes SolidWorks, Waltham, Massachusetts) by using a simplified steady-state model without consideration of pulsatile flow behavior. We simulated 3 cooling catheter configurations with different balloon arrays: 1) 1 balloon with an 80-mm length, 2) 2 balloons with 40-mm lengths, and 3) 4 balloons with 20-mm lengths, all of which had a similar total surface area for heat exchange. Balloon wall thickness was $15 \mu \mathrm{m}$.

The computational mesh grid consisted of rectangular parallel-pipe-shaped fluid, solid, and partial cells, whose boundaries were orthogonal to the axes of the Cartesian global coordinate system. The meshing of the fluid domain presented approximately 2 million cells with mesh refinement near the balloon wall, where the heat transfer takes place. For simulation, the distal catheter tip with the heat exchanging balloons
Germany). The complete installation of the in vitro bench test is illustrated in Fig 3.

This circuit was filled with a blood substitute consisting of a water-glycerine mixture (56\% glycerin, $44 \%$ bi-distilled water), which approximated the rheologic properties of human blood (dynamic viscosity of $3.6 \mathrm{cP}$ at $37^{\circ} \mathrm{C}$ ). Constant warming to a temperature of $37^{\circ} \mathrm{C}$ proximal to the cooling catheter inlet was provided by a heating circulator bath (Haake DC10-B3; Thermo Haake, Karlsruhe, Germany). Pulsatile circulation of the blood substitute was achieved by a gear pump (Optima 1000 PD12; Diener Precision Pumps, Embrach, Switzerland). The distal part of the cooling catheter system with the heat-exchange balloons was inserted into the circuit via a hemostatic valve.

The coolant $(0.9 \%$ sodium chloride $)$ was circulated inside the cooling catheter circuit by means of a roller pump (Behrotest PLP 220 with pump head PPH 303; Behr Labor-Technik, Düsseldorf, Germany) at a flow rate of $100 \mathrm{~mL} / \mathrm{min}$. The cool- 

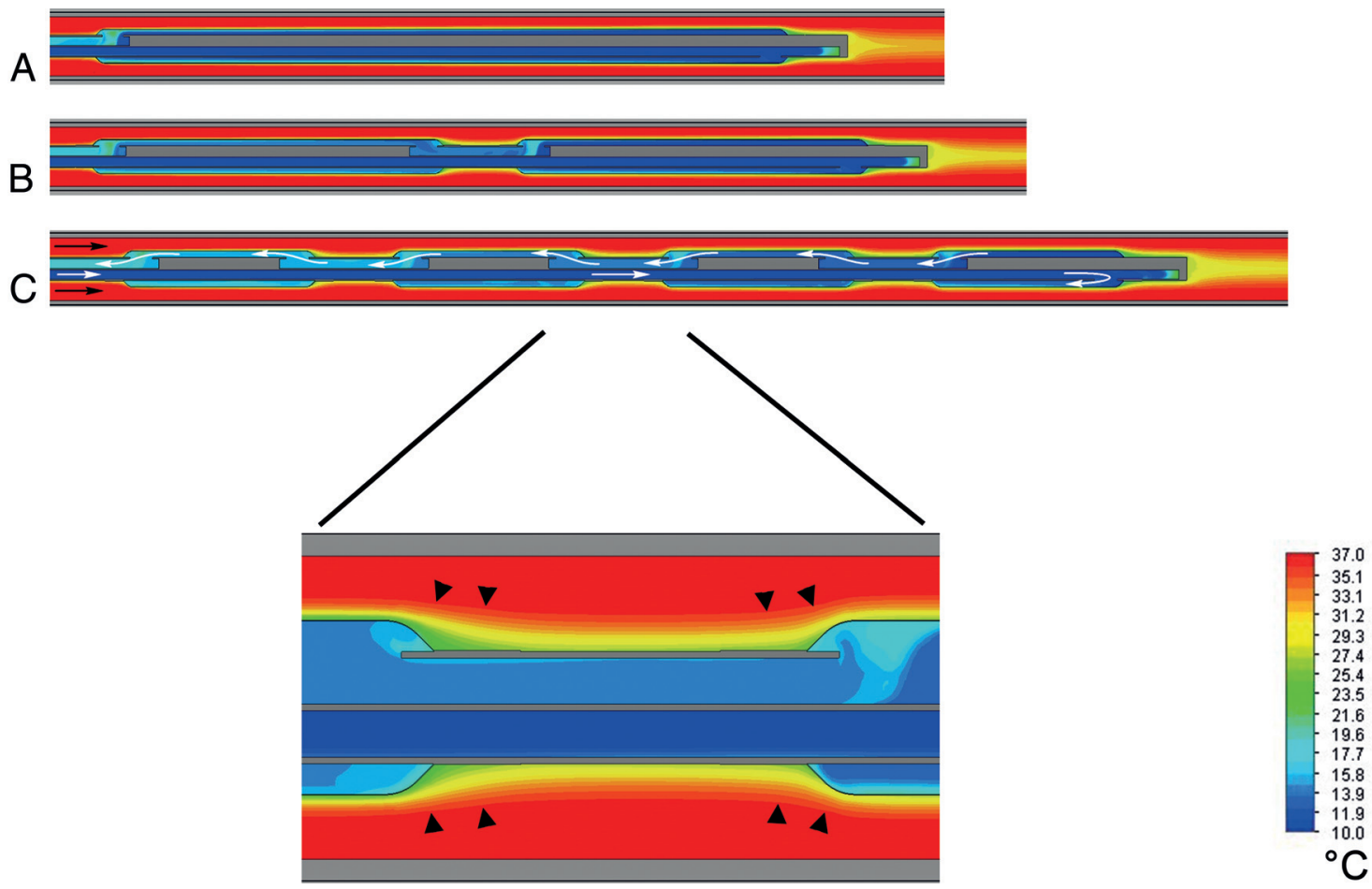

FIG 5. Temperature profiles derived from numeric simulation are illustrated along the cooling catheters with different serial balloon arrays (all 4-mm diameters): $1 \times 80 \mathrm{~mm}(A) ; 2 \times 40 \mathrm{~mm}(B)$; and $4 \times 20 \mathrm{~mm}(C)$. C. The direction of blood flow is indicated by small black arrows, and the direction of coolant flow inside the catheter lumina is indicated by small white arrows. Temperatures are not visualized on solid catheter material (gray); larger rectangular gray areas represent blocked endoluminal portions, which enable serial coolant flow through respective balloons. The magnified inlet image shows the junction between adjacent balloons: Disruption of thermal boundary layers is depicted at both junction zones (small black arrowheads). Color coding corresponds to respective fluid temperature $\left(10^{\circ} \mathrm{C}-37^{\circ} \mathrm{C}\right.$ range; see scale).

ant temperature was kept constant at $\sim 6^{\circ} \mathrm{C}$ provided by a circulation thermostat (Ministat 125; Peter Huber Kältemaschinenbau, Offenburg, Germany). Flow rates of both circuits were constantly measured by ultrasonic flow meters (M-2111; Malema Engineering, Boca Raton, Florida). Pressures were measured inside the cooling catheter circuit proximal to the catheter inlet (HPSA-B10DVAB-020-G; Althen, Kelkheim, Germany) and inside the "blood circuit" proximal to the cooling balloons (HPSA-B10DVAC-0,4BG; Althen). The coolant temperature was measured at the catheter inlet and outlet hub with precision fine-wire thermocouples (5TC-KK-KI-24-2 m; Omega Engineering, Stamford, Connecticut). Temperatures inside the blood circuit were measured by customized 1-mm mineral-insulated thermocouples (NiCr-Ni; Temperatur Messelemente Hettstedt, Maintal, Germany) proximal and distal to the cooling catheter system. To compensate for temperature stream layering of cooled and noncooled fluid distal to the balloon cooling catheter, we positioned the distal point of temperature measurement behind a flow indicator (CheMobil PMP; Bürkle, Bad Bellingen, Germany), which had an integrated impeller function for mixing of different temperature fluid layers.

Three similar prototypes of the cooling catheter were tested inside the blood circuit. We performed measurements separately at 2 predefined flow rates of the blood circuit: $400 \mathrm{~mL}$ / min, which is compatible with the mean blood flow rate of a human CCA $(389 \pm 73$ and $381 \pm 79 \mathrm{~mL} / \mathrm{min}$; left and right CCA, respectively ${ }^{18}$ ), and $250 \mathrm{~mL} / \mathrm{min}$, which aims to simulate the CCA flow reduction caused by an MCA occlusion (150 \pm 31 and $145 \pm 27 \mathrm{~mL} / \mathrm{min}$; normal left and right MCA flow rate, respectively ${ }^{18}$ ), neglecting potential autoregulatory flow changes. All temperature, fluid pressure, and flow data were continuously recorded and processed with an in-house-programmed software (LabVIEW 2013; National Instruments Corporation, Austin, Texas). After the start of the blood substitute and coolant pumps and a brief transient time of 2 minutes to allow steady-state flow conditions, recording of temperature data was performed for 2 minutes (100 temperature measurements per second). The temperature data were timeaveraged over the 3 catheter prototypes.

\section{RESULTS}

The results of the numeric simulation are depicted in Fig 4, showing the temperature gradient across the cooling catheter for the 3 tested balloon arrays. The increasing number of balloons correlated with a higher blood-cooling performance, though the total heat-exchange surface area remained the same for all balloon arrays. This improved heat exchange for serial balloon alignments may be attributed to a disruption of the thermal boundary layer and increase of flow convection between the adjacent balloons (Fig 5). The highest temperature decrease across the catheter was $-1.63^{\circ} \mathrm{C}$ by using a serial array of $4 \times 20 \mathrm{~mm}$ balloons, while a single $1 \times 80 \mathrm{~mm}$ balloon provided a temperature decrease of only $-1.21^{\circ} \mathrm{C}$.

On the basis of these results, the first prototype of the balloon cooling catheter was manufactured, which consisted of 4 
polyamide balloons (Bavaria Medizin Technologie, Wessling, Germany) with a diameter of $4 \mathrm{~mm}$, a length of $20 \mathrm{~mm}$, and a wall thickness of $15 \mu \mathrm{m}$ each. These were serially arranged at the catheter tip communicating with 2 separate catheter lumina that constituted the closed-loop cooling circuit. The third central "working lumen" with a diameter of $1 \mathrm{~mm}$ had an end-hole at the catheter tip allowing passage of a $2.5 \mathrm{~F}$ microcatheter and thus distal access for MT treatment with a stent retriever device (Fig 6).

The in vitro experiments in the artificial blood circuit revealed a mean temperature gradient induced by the cooling catheter system (time-averaged over 3 similar catheter prototypes) of $2.17 \pm$ $0.07^{\circ} \mathrm{C}$ and $1.55 \pm 0.06^{\circ} \mathrm{C}$ at "blood" flow rates of 250 and 400 $\mathrm{mL} / \mathrm{min}$, respectively (Fig 7). During cooling, the temperature of the coolant inside the balloon catheter circuit increased by $5.46 \pm$ $.55^{\circ} \mathrm{C}$ and $5.95 \pm 0.76^{\circ} \mathrm{C}$ at 250 and $400 \mathrm{~mL} / \mathrm{min}$, respectively. The mean pressure drop of the coolant within the cooling catheter system was 4.33 bar.

\section{DISCUSSION}

In this in vitro feasibility study, the blood-cooling performance of a newly developed balloon cooling catheter system designed for combined selective intracarotid TH and MT in acute stroke due to large-artery occlusion was investigated. Intra-CCA blood cooling was feasible with a mean temperature drop of $1.55^{\circ} \mathrm{C}$. This result was closely matched by the numeric simulation (temperature drop of $1.63^{\circ} \mathrm{C}$ ), which underlines the value of numeric simulation as a developmental tool.

These measured temperature drops imply an in vivo blood outlet temperature of $\approx 35.5^{\circ} \mathrm{C}$ (based on a physiologic temperature of $37^{\circ}$ ). Clinical trials evaluating mild $\mathrm{TH}$ aim for optimum target temperatures between $33^{\circ} \mathrm{C}$ and $35^{\circ} \mathrm{C} .{ }^{11}$ In both the numeric and in vitro models, however, temperatures were kept constant to $37^{\circ} \mathrm{C}$ proximal to the inlet of the balloon catheter system, which neglects the in vivo recirculation effect of already cooled blood. The latter may add to a further decrease in blood temperature distal to the balloon catheter system in an in vivo application. The latter effects should be dependent on the duration of cooling. Moreover, at a lowered "blood" flow rate of $250 \mathrm{~mL} / \mathrm{min}$ reproducing the reduction of CCA blood flow because of distal MCA occlusion, cooling reached $-2.17^{\circ} \mathrm{C}$, which more closely approached the target of mild $\mathrm{TH}$. This effect of heat exchange improvement may likely be explained by the longer contact time between balloons and blood substitute at lower flow rates.

It can be assumed that the blood temperature distal to the balloon does not necessarily represent the parenchymal brain temperature due to further heat loss through the arterial walls. However, heat transfer with surrounding tissues is limited in larger vessels and occurs predominantly in smaller arteries and capillaries, suggesting that cooling is mostly transferred to the region of perfused brain tissue: first, the ischemic penumbra; then, following successful MT treatment, the ischemic core.

With regard to the cooling catheter design, numeric simulation helped to improve the heat exchange performance by $>30 \%$ by using the serial balloon array at the catheter tip $(4 \times 20 \mathrm{~mm})$. The observed disruption of thermal boundary layers and increase of flow convection between the adjacent balloons appear crucial

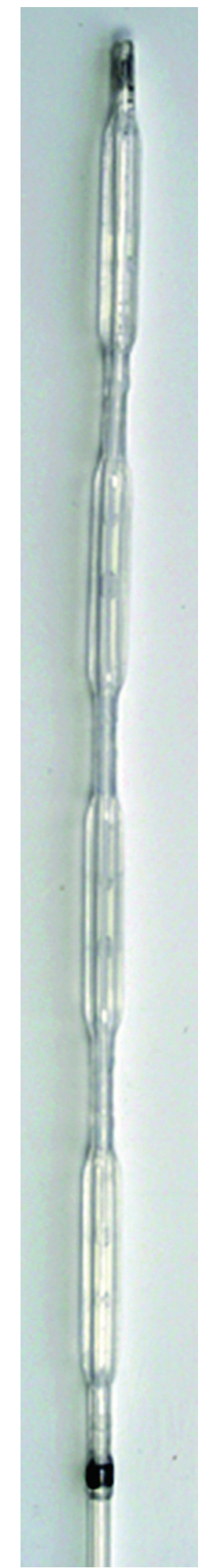

FIG 6. Photograph of the cooling catheter tip with 4 sequentially arrayed balloons. 
Flow rate of blood subsitute $(\mathrm{ml} / \mathrm{min})$

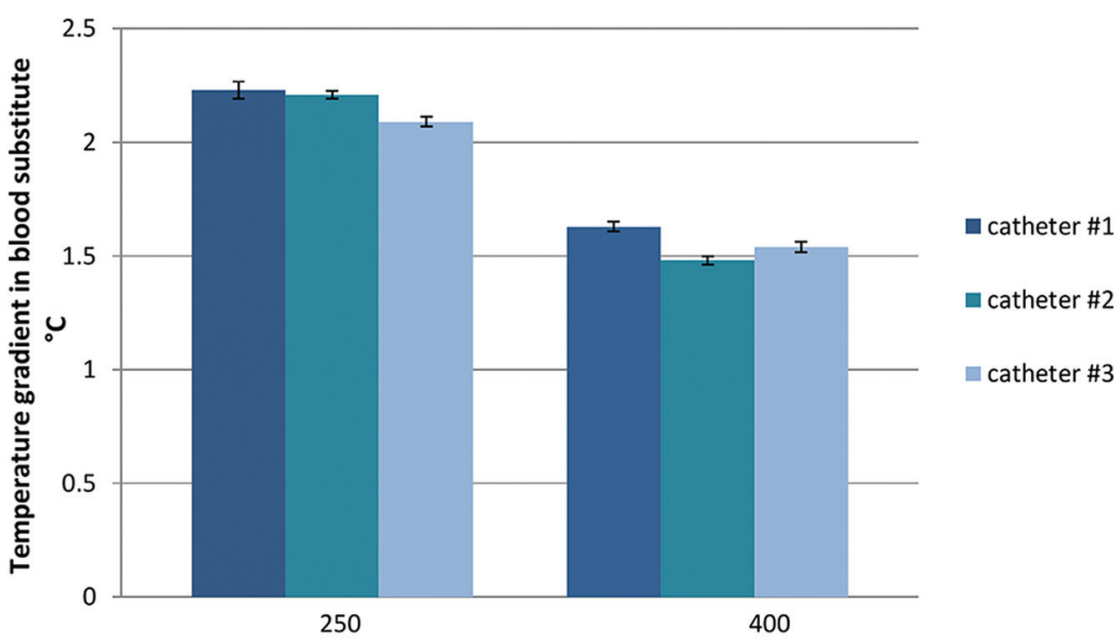

induction of cooling before vessel recanalization within a single procedure. An optimized balloon catheter design with a serial array of 4 balloons improved the cooling capacity of the system by $>30 \%$, reaching the target of mild $\mathrm{TH}$ with a blood temperature decrease of $1.6^{\circ} \mathrm{C}-2.2^{\circ} \mathrm{C}$.

Disclosures: Giorgio Cattaneo-RELATED: Grant: German Federal Ministry of Research and Education*; UNRELATED: Employment: Acandis GmbH \& Co. KG (Pforzheim, Germany); Grants/Grants Pending: German Federal Ministry of Research and Education.* Martin Schumacher, Julia Wolfertz, Tobias Jost-RELATED: Grant: Federal Ministry of Education and Research, ${ }^{*}$ Comments: national grant; Support for Travel to Meetings for the Study or Other Purposes: Federal Ministry of Education and Research; Fees for Participation in Review Activities such as Data Monitoring Boards, Statistical Analysis, Endpoint Committees, and the Like: Federal Ministry of Education and Research*; UNRELATED: Board Membership: Acandis GmbH \& Co. KG. induced by 3 tested cooling catheter prototypes (balloon array; $4 \times 20 \mathrm{~mm}$ ) at 2 predefined flow rates of blood substitute.

for optimization of cooling performance in view of the limited volume within the CCA lumen and in a limited time window.

Our in vitro model has several limitations: Straight plastic tubing has different thermal conductivity than arterial walls, and the artificial blood substitute has different thermal conductivity than blood. Further assumptions were made relative to a constant pulsatile blood flow and straight vessel anatomy with constant diameters, which is not like individual human in vivo variations. Moreover, the following assumptions are limitations to the computational fluid dynamics model: the rigid and adiabatic behavior of vessel walls, an immobile centered balloon catheter tip with a simplified symmetric 2-lumen catheter model, data base-derived values of human rheology, estimated heat loss along whole catheter length, and a simplified steadystate flow model with nonpulsatile flow.

Intracarotid cold saline infusions have been investigated as an alternative approach to selective brain hypothermia for the treatment of acute ischemic stroke. Thus, a rapid induction of moderate brain hypothermia was achieved in theoretic models of selective brain cooling. ${ }^{19-22}$ However, the in vivo experiments with infusion of cold isotonic saline $\left(4^{\circ} \mathrm{C}-17^{\circ} \mathrm{C} ; 33 \mathrm{~mL} / \mathrm{min}\right.$ for 10 minutes) into the ICA could only demonstrate a temperature drop of $0.84^{\circ} \mathrm{C}$ within the jugular venous bulb; these experiments were performed in patients undergoing diagnostic cerebral angiography. ${ }^{23}$ Moreover, hemodilution effects and volume overload may be other limiting factors for longer application of this technique in patients with acute stroke.

As the next step, we will perform an in vivo study of intracarotid blood cooling that will aim to evaluate the safety and efficacy of the presented balloon catheter system in a large animal model of temporary MCA ischemia and reperfusion.

\section{CONCLUSIONS}

In this in vitro study, the feasibility of intracarotid (CCA) blood cooling was demonstrated by using a new 3-lumen balloon catheter system, which was designed for combined selective TH and MT in acute stroke due to large cerebral artery occlusion. This approach appears particularly promising due to rapid and early
Stephan Meckel—RELATED: Grant: Federal Ministry of Education and Research, Germany (Federal Ministry of Education and Research grant 13GW0015B)*; Consulting Fee or Honorarium: Acandis GmbH \& Co. KG, Comments: member of Scientific Advisory Board; Support for Travel to Meetings for the Study or Other Purposes: Acandis GmbH \& Co. KG; UNRELATED: Travel/Accommodations/Meeting Expenses Unrelated to Activities Listed: Covidien, MicroVention, Stryker. *Money paid to the institution.

\section{REFERENCES}

1. Bernard SA, Gray TW, Buist MD, et al. Treatment of comatose survivors of out-of-hospital cardiac arrest with induced hypothermia. N Engl J Med 2002;346:557-63 CrossRef Medline

2. Hypothermia after Cardiac Arrest Study Group. Mild therapeutic hypothermia to improve the neurologic outcome after cardiac arrest. N Engl J Med 2002;346:549-56 CrossRef Medline

3. Shankaran S, Laptook AR, Ehrenkranz RA, et al; National Institute of Child Health and Human Development Neonatal Research Network. Whole-body hypothermia for neonates with hypoxic-ischemic encephalopathy. $N$ Engl J Med 2005;353:1574-84 CrossRef Medline

4. Azzopardi DV, Strohm B, Edwards AD, et al; TOBY Study Group. Moderate hypothermia to treat perinatal asphyxial encephalopathy. N Engl J Med 2009;361:1349-58 CrossRef Medline

5. Yenari MA, Han HS. Neuroprotective mechanisms of hypothermia in brain ischaemia. Nat Rev Neurosci 2012;13:267-78 CrossRefMedline

6. Piironen K, Tiainen M, Mustanoja S, et al. Mild hypothermia after intravenous thrombolysis in patients with acute stroke: a randomized controlled trial. Stroke 2014;45:486-91 CrossRef Medline

7. De Georgia MA, Krieger DW, Abou-Chebl A, et al. Cooling for Acute Ischemic Brain Damage (COOL AID): a feasibility trial of endovascular cooling. Neurology 2004;63:312-17 CrossRef Medline

8. Hemmen TM, Raman R, Guluma KZ, et al; ICTuS-L Investigators. Intravenous thrombolysis plus hypothermia for acute treatment of ischemic stroke (ICTuS-L): final results. Stroke 2010;41:2265-70 CrossRef Medline

9. Kammersgaard LP, Rasmussen BH, Jørgensen HS, et al. Feasibility and safety of inducing modest hypothermia in awake patients with acute stroke through surface cooling: a case-control study - the Copenhagen Stroke Study. Stroke 2000;31:2251-56 CrossRef Medline

10. van der Worp HB, Macleod MR, Kollmar R; European Stroke Research Network for Hypothermia (EuroHYP). Therapeutic hypothermia for acute ischemic stroke: ready to start large randomized trials? J Cereb Blood Flow Metab 2010;30:1079-93 CrossRef Medline 
11. Wu TC, Grotta JC. Hypothermia for acute ischaemic stroke. Lancet Neurol 2013;12:275-84 CrossRef Medline

12. Berkhemer OA, Fransen PS, Beumer D, et al. A randomized trial of intraarterial treatment for acute ischemic stroke. N Engl J Med 2015; 372:11-20 CrossRef Medline

13. Campbell BC, Mitchell PJ, Kleinig TJ, et al; EXTEND-IA Investigators. Endovascular therapy for ischemic stroke with perfusion-imaging selection. N Engl J Med 2015;372:1009-18 CrossRef Medline

14. Goyal M, Demchuk AM, Menon BK, et al; ESCAPE Trial Investigators. Randomized assessment of rapid endovascular treatment of ischemic stroke. N Engl J Med 2015;372:1019-30 CrossRef Medline

15. Khatri R, McKinney AM, Swenson B, et al. Blood-brain barrier, reperfusion injury, and hemorrhagic transformation in acute ischemic stroke. Neurology 2012;79:S52-57 CrossRef Medline

16. Pan J, Konstas AA, Bateman B, et al. Reperfusion injury following cerebral ischemia: pathophysiology, MR imaging, and potential therapies. Neuroradiology 2007;49:93-102 CrossRef Medline

17. Avolio AP. Multi-branched model of the human arterial system. Med Biol Eng Comput 1980;18:709-18 CrossRef Medline

18. Zhao M, Amin-Hanjani S, Ruland S, et al. Regional cerebral blood flow using quantitative MR angiography. AJNR Am J Neuroradiol 2007;28:1470-73 CrossRef Medline

19. Konstas AA, Neimark MA, Laine AF, et al. A theoretical model of selective cooling using intracarotid cold saline infusion in the human brain. J Appl Physiol (1985) 2007;102:1329-40 Medline

20. Neimark MA, Konstas AA, Choi JH, et al. The role of intracarotid cold saline infusion on a theoretical brain model incorporating the circle of Willis and cerebral venous return. Conf Proc IEEE Eng Med Biol Soc 2007;2007:1140 -43 Medline

21. Neimark MA, Konstas AA, Laine AF, et al. Heat transfer model of hyporthermic intracarotid infusion of cold saline for stroke therapy. Conf Proc IEEE Eng Med Biol Soc 2006;1:363-66 Medline

22. Neimark MA, Konstas AA, Laine AF, et al. Integration of jugular venous return and circle of Willis in a theoretical human model of selective brain cooling. J Appl Physiol (1985) 2007;103:1837-47 CrossRef Medline

23. Choi JH, Marshall RS, Neimark MA, et al. Selective brain cooling with endovascular intracarotid infusion of cold saline: a pilot feasibility study. AJNR Am J Neuroradiol 2010;31:928-34 CrossRef Medline 